\title{
The crystal structure of 2-aminoisophthalic acid, $\mathrm{C}_{8} \mathrm{H}_{7} \mathrm{NO}_{4}$
}

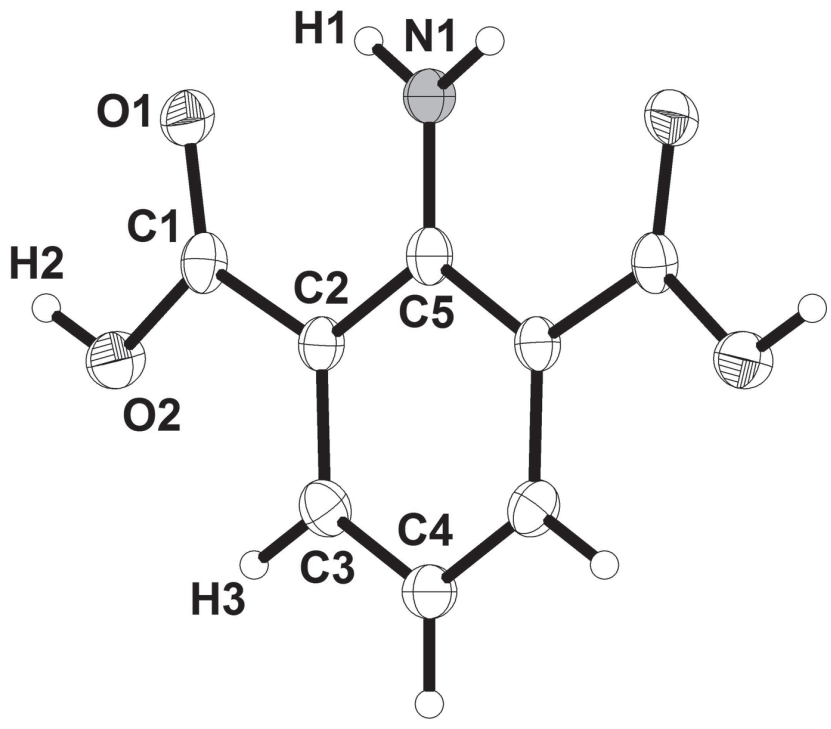

https://doi.org/10.1515/ncrs-2019-0783

Received October 21, 2019; accepted December 28, 2019; available online January 18,2020

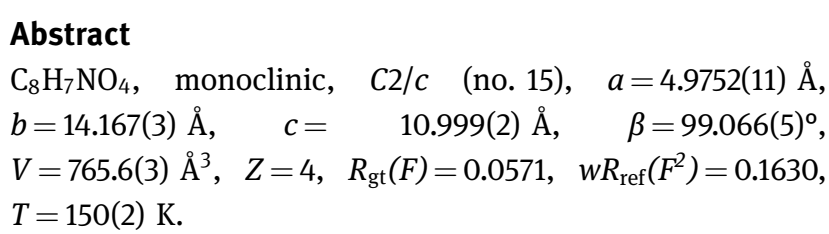

CCDC no.: 1974535

The title molecular structure is shown in the figure (only the asymmetric unit is labelled). Table 1 contains crystallographic data and Table 2 contains the list of the atoms including atomic coordinates and displacement parameters.

\section{Source of materials}

All of the starting materials are commercially available and used as received. The title compound, 2-aminoisophthalic acid $(1.81 \mathrm{~g}, 1 \mathrm{mmol})$, was added to a THF solution $(20 \mathrm{~mL})$ at room temperature. After stirring for $10 \mathrm{~min}$, the solution

*Corresponding author: Bin Cai, School of Chemistry and Chemical Engineering, Zhoukou Normal University, Zhoukou, Henan Province 466001, P.R. China, e-mail: caib@actinide.org. https://orcid.org/ 0000-0002-3573-5651

Meng-En Zhu, Yu-Ning Meng and Kun Li: School of Chemistry and Chemical Engineering, Zhoukou Normal University, Zhoukou, Henan Province 466001, P.R. China

๑ Open Access. @ 2020 Bin Cai et al., published by De Gruyter. (cc)BY
Table 1: Data collection and handling.

\begin{tabular}{ll}
\hline Crystal: & Needle, colorless \\
Size: & $0.3 \times 0.25 \times 0.1 \mathrm{~mm}$ \\
Wavelength: & Mo $K \alpha$ radiation $(0.71073 \AA$ A $)$ \\
$\mu:$ & $0.13 \mathrm{~mm}^{-1}$ \\
Diffractometer, scan mode: & Bruker APEX-II, $\varphi$ and $\omega$-scans \\
$\theta_{\text {max }}$, completeness: & $25.2^{\circ},>98 \%$ \\
$N(h k l)_{\text {measured }}, N(h k l)_{\text {unique }}, R_{\text {int }}:$ & $5580,675,0.075$ \\
Criterion for $I_{\text {obs }}, N(h k l)_{\text {gt }}:$ & $I_{\text {obs }}>2 \sigma\left(I_{\text {obs }}\right), 487$ \\
$N(\text { param })_{\text {refined }}:$ & 66 \\
Programs: & Bruker programs [1], SHELX [2], \\
& OLEX2 [3, 4] \\
\hline
\end{tabular}

Table 2: Fractional atomic coordinates and isotropic or equivalent isotropic displacement parameters $\left(\AA^{2}\right)$.

\begin{tabular}{lrrrr}
\hline Atom & $\boldsymbol{x}$ & $\boldsymbol{y}$ & $\boldsymbol{z}$ & $\boldsymbol{U}_{\text {iso }}{ }^{*} \boldsymbol{U}_{\text {eq }}$ \\
\hline $\mathrm{N} 1$ & 1.000000 & $0.7890(2)$ & 0.750000 & $0.0217(8)$ \\
$\mathrm{H} 1$ & $0.880(6)$ & $0.822(2)$ & $0.703(3)$ & $0.036(8)^{\star}$ \\
$\mathrm{O} 1$ & $0.5330(4)$ & $0.77617(12)$ & $0.59221(16)$ & $0.0241(6)$ \\
$\mathrm{O} 2$ & $0.3897(4)$ & $0.63144(12)$ & $0.53111(17)$ & $0.0269(6)$ \\
$\mathrm{H} 2$ & 0.258772 & 0.662500 & 0.493303 & $0.040^{*}$ \\
$\mathrm{C} 1$ & $0.5631(5)$ & $0.68953(19)$ & $0.5970(2)$ & $0.0202(7)$ \\
$\mathrm{C} 2$ & $0.7898(5)$ & $0.64106(17)$ & $0.6751(2)$ & $0.0182(7)$ \\
$\mathrm{C} 3$ & $0.7968(5)$ & $0.54292(19)$ & $0.6763(2)$ & $0.0228(7)$ \\
$\mathrm{H} 3$ & 0.658099 & 0.509021 & 0.624983 & $0.027^{*}$ \\
$\mathrm{C} 4$ & 1.000000 & $0.4931(3)$ & 0.750000 & $0.0256(9)$ \\
$\mathrm{H} 4$ & 1.000004 & 0.426024 & 0.749999 & $0.031^{*}$ \\
$\mathrm{C} 5$ & 1.000000 & $0.6937(3)$ & 0.750000 & $0.0194(9)$ \\
\hline
\end{tabular}

was filtered and let evaporate. Several days later, a large number of colorless crystals were harvested, yield $83.5 \%$ (based on 2-aminoisophthalic acid).

\section{Experimental details}

The structure was solved by direct methods with the SHELXS program. All $\mathrm{H}$-atoms from $\mathrm{C}, \mathrm{N}$ and $\mathrm{O}$ atoms were positioned with idealized geometry and refined $\left(U_{\text {iso }}(\mathrm{H})=1.2 U_{\text {eq }}(\mathrm{C})\right.$, $1.2 U_{\text {eq }}(\mathrm{N})$ and $U_{\text {iso }}(\mathrm{H})=1.5 U_{\text {eq }}(\mathrm{O}$, respectively), for all $\mathrm{H}$ atoms) using a riding model with $\mathrm{C}-\mathrm{H}=0.950 \AA$, $\mathrm{N}-$ $\mathrm{H}=0.863 \AA$ and $\mathrm{O}-\mathrm{H}=0.840 \AA$, respectively). 


\section{Comment}

To the best of our knowledge, there is no report on the crystal structure of 2-aminoisophthalic acid except a cocrystal structure with norfloxacin [5]. Some examples of mono- or disubstituted for amino group of 2-aminoisophthalic acid or its carboxylate esters have been reported [6-10]. Thus, we herein report the crystal structure of 2-aminoisophthalic acid.

As shown in the figure, 2-aminoisophthalic acid with the molecule formula of $\mathrm{C}_{8} \mathrm{H}_{7} \mathrm{NO}_{4}$, crystallises in the monoclinic space group, $C 2 / c$ with the molecule located on a twofold axis. Consequently the atoms $\mathrm{H} 4, \mathrm{C} 4, \mathrm{C} 1$ and N1 are located on this axis (see the figure) and non-hydrogen atoms are nearly co-planar. There are two kinds of hydrogen bonds: each molecule forms two intramolecular $\mathrm{N}-\mathrm{H}$. . O hydrogen bonds. Intermolecular $\mathrm{O}-\mathrm{H} \cdots \mathrm{O}$ link adjacent molecules to a one-dimensional supramolecular structure in a head-to-tail mode. All bond lengths and angles of the title compound are comparable to its analogue structures [5-10].

Acknowledgements: This work was supported by the Education Department of Henan Province Natural Science Research Program (18B150029), Key Scientific and Technological Research Projects in Henan Province (192102210028) and the National Natural Science Foundation of China (51602358).

\section{References}

1. Bruker, SAINT v8.37A, Bruker AXS Inc, Madison, WI, USA (2015).
2. Sheldrick, G. M.: A short history of SHELX. Acta Crystallogr. A64 (2008) 112-122.

3. Bourhis, L. J.; Dolomanov, O. V.; Gildea, R. J.; Howard, J. A. K.; Puschmann, H.: The anatomy of a comprehensive constrained, restrained refinement program for the modern computing environment-Olex2 dissected. Acta Crystallogr. A71 (2015) 59-75.

4. Dolomanov, O. V.; Bourhis, L. J.; Gildea, R. J.; Howard, J. A. K.; Puschmann, H.: OLEX2: a complete structure solution, refinement and analysis program. J. Appl. Crystallogr. 42 (2009) 339-341.

5. Huang, X.-F.; Zhang, Z.-H.; Zhang, Q.-Q.; Wang, L.-Z.; He, M.-Y.; Chen, Q.; Song, G.-Q.; Wei, L.; Wang, F.; Du, M.: Norfloxacin salts with benzenedicarboxylic acids: charge-assisted hydrogen-bonding recognition and solubility regulation. CrystEngComm 15 (2013) 6090-6100.

6. Hong, X.; Wang, H.; Liu, B.; Xu, B.: Ruthenium-catalyzed double-fold $\mathrm{C}-\mathrm{H}$ tertiary alkoxycarbonylation of arenes using di-tert-butyl dicarbonate. Chem. Commun. 50 (2014) 14129-14132.

7. Field, J. E.; Hill, T.; Venkataraman, D.: Bridged triarylamines: A new class of heterohelicenes. J. Org. Chem. 68 (2003) 6071-6078.

8. Moczar, I.; Huszthy, P.; Bathori, N.; Czugler, M.: A 2:1:1 2(2-carboxy-phenyl-amino)-isophthalic acid-ethyl acetatebutan-2-one inclusion complex. Acta Cryst. E60 (2004) 01067-01068.

9. Surampudi, S. K.; Nagarjuna, G.; Okamoto, D.; Chaudhuri, P. D.; Venkataraman, D.: Apical Functionalization of Chiral Heterohelicenes. J. Org. Chem. 77 (2012) 2074-2079.

10. Shimizu, M.; Nakatani, M.: Blue-to-green delayed fluorescence of 2-aminoisophthalic acid diesters dispersed in polymer film. Eur. J. Org. Chem. 32 (2017) 4695-4702. 